\title{
Improving psychological treatment for obesity. Which eating behaviours should we target?
}

Citation for published version (APA):

Carter, F. A., \& Jansen, A. (2012). Improving psychological treatment for obesity. Which eating behaviours should we target? Appetite, 58(3), 1063-1069. https://doi.org/10.1016/j.appet.2012.01.016

Document status and date:

Published: 01/06/2012

DOI:

10.1016/j.appet.2012.01.016

Document Version:

Publisher's PDF, also known as Version of record

Document license:

Taverne

\section{Please check the document version of this publication:}

- A submitted manuscript is the version of the article upon submission and before peer-review. There can be important differences between the submitted version and the official published version of record.

People interested in the research are advised to contact the author for the final version of the publication, or visit the DOI to the publisher's website.

- The final author version and the galley proof are versions of the publication after peer review.

- The final published version features the final layout of the paper including the volume, issue and page numbers.

Link to publication

\footnotetext{
General rights rights.

- You may freely distribute the URL identifying the publication in the public portal. please follow below link for the End User Agreement:

www.umlib.nl/taverne-license

Take down policy

If you believe that this document breaches copyright please contact us at:

repository@maastrichtuniversity.nl

providing details and we will investigate your claim.
}

Copyright and moral rights for the publications made accessible in the public portal are retained by the authors and/or other copyright owners and it is a condition of accessing publications that users recognise and abide by the legal requirements associated with these

- Users may download and print one copy of any publication from the public portal for the purpose of private study or research.

- You may not further distribute the material or use it for any profit-making activity or commercial gain

If the publication is distributed under the terms of Article $25 \mathrm{fa}$ of the Dutch Copyright Act, indicated by the "Taverne" license above, 
Research review

\title{
Improving psychological treatment for obesity. Which eating behaviours should we target? is $^{2}$
}

\author{
Frances A. Carter ${ }^{\mathrm{a}, *}$, Anita Jansen ${ }^{\mathrm{b}}$ \\ ${ }^{a}$ Department of Psychological Medicine, University of Otago, Christchurch and Canterbury District Health Board, P.O. Box 4345, Christchurch, New Zealand \\ ${ }^{\mathrm{b}}$ Department of Clinical Psychological Science, Maastricht University, Maastricht, The Netherlands
}

\section{A R T I C L E I N F O}

\section{Article history:}

Received 9 June 2011

Received in revised form 4 December 2011

Accepted 17 January 2012

Available online 25 January 2012

\section{Keywords:}

Obesity

Eating behaviour

Grazing

Binge eating

Behavioural assessment

Cognitive behaviour therapy

Treatment

\begin{abstract}
A B S T R A C T
People who are obese and want to lose weight without surgery deserve the best treatment that we can offer. In the absence of robust and enduring treatment effects for psychological interventions for obesity, it is useful to return to first principles. From a behavioural perspective, the first task is to identify the full range of target eating behaviours involved in obesity. Surprisingly, a consensus on the key target eating behaviours typically involved in obesity does not seem to currently exist. In this opinion piece, we discuss which eating behaviours might be important to consider when treating obesity, and provide a self-report questionnaire that aims to identify these behaviours (see Supplementary material). We believe that it is important to be aware of the full range of eating behaviours that are potentially relevant to obesity, as different eating behaviours may be problematic for different people. Target eating behaviours associated with obesity may also be different from those of key relevance to eating disorders. Factors that should be taken into account when assessing target eating behaviours and developing effective treatments for obesity are also discussed. Particular attention is paid to 'grazing,' a relatively neglected high risk eating behaviour for weight gain.
\end{abstract}

(c) 2012 Elsevier Ltd. All rights reserved.

\section{Introduction}

Obesity is an increasingly pervasive problem (World Health Organization, 2011) that places people at elevated risk for a broad range of adverse health consequences (Hevener \& Febbraio, 2010; Kopelman, 2007; Sturm, 2002). Non-surgical approaches to obesity have frequently been found to be ineffective, especially in the longer term (Barte et al., 2010; Wu, Gao, Chen, \& van Dam, 2009). Bariatric surgery is effective, but it is expensive and not without risks (Flum et al., 2009). Effective non-surgical interventions for obesity seem to be elusive, and the challenge of finding them has "humbled one research group after another" (Brownell, 2010, p. 717). While major change will need to occur in our social environment to address the world's obesity problem, we take the 'pragmatic perspective' that individual patients deserve the best treatment that we can offer (Brownell, 2010). Effective non-surgical interventions are needed for people who are obese and want help to either lose weight, or at least not gain further weight. Psychological interventions also have the potential to help bariatric

\footnotetext{
Acknowledgements: The authors wish to thank Dr. Jennifer Jordon (clinical psychologist) and Dr. Jane Elmslie (dietitian) for their helpful comments on an earlier version of this manuscript.

* Corresponding author.

E-mail address: frances.carter@otago.ac.nz (F.A. Carter).
}

surgery patients obtain the best outcome from surgery (Ashton, Drerup, Windover, \& Heinberg, 2009; Saunders, 2004b).

In the absence of robust and enduring treatment effects, it is useful to start from first principles when considering psychological approaches to obesity. From a behavioural perspective, the first task is to identify the full range of target eating behaviours involved in obesity. Surprisingly, this is less clear than might be expected. We also need to be careful not to assume that concepts inherited from eating disorders, will translate directly to obesity.

The present paper is an opinion piece, where we discuss which eating behaviours might be important to consider when treating obesity, and provide a self-report questionnaire that aims to identify these behaviours. Factors that should be taken into account when assessing target eating behaviours and developing effective treatments for obesity are also discussed. Particular attention is paid to 'grazing,' a relatively neglected high risk eating behaviour for weight gain. This paper focuses primarily on target eating behaviours for obesity. Although other factors are touched upon, it is beyond the scope of this paper to examine behaviours of relevance to obesity that don't involve eating (e.g., sedentary behaviour, avoidance of feedback regarding weight) or non-behavioural factors of relevance to obesity such as affect and cognitions. It is also outside the scope of this paper to systematically review the evidence supporting hypothesised mechanisms involved in overeating (e.g., emotional eating, dietary restraint and disinhibition 
and hedonic eating), the treatment approaches to overeating or Public Health approaches to encouraging healthy eating.

\section{Identification of target eating behaviours involved in obesity}

\section{Background}

Behavioural interventions for obesity have a long history. For example, in a seminal paper, Stuart (1967) wrote that "the first step in self-control is a precise analysis of the response to be controlled and its antecedent and consequent conditions" (p. 357). How far have we come since this statement? Are we now able to describe the full range of 'responses' that are likely to 'need to be controlled' when treating people who are obese? Have sufficient observational studies been conducted to know what the target eating behaviours involved in obesity might be? It would be expected that we would now be in a strong position to describe the full range of problem eating behaviours that are likely to be associated with obesity.

Literature searches were conducted using the terms 'obesity,' 'eating behaviour,' and 'weight' in titles and/or key words, using Medline and Psychinfo databases. No studies were found which sought to identify the target behaviours involved in obesity. Most of the articles identified by these searches studied behaviour in a more general sense, such as eating behaviour being 'unhealthy', 'uncontrolled', 'disordered', 'disinhibited', or 'restrained,' and did not provide insight into the range of specific target eating behaviours related to obesity. We are aware of excellent articles describing behavioural assessment and treatment of obesity (Cooper, Fairburn, \& Hawker, 2003; Laessle, 2005; Smith West, Gore, \& Lueders, 2007; Wadden \& Phelan, 2002; Wadden \& Stunkard, 2002; Wilson, 1995), including a helpful checklist of barriers to weight loss (Cooper et al., 2003). However again, there does not seem to be a consensus amongst psychological researchers and clinicians on the full range of key target eating behaviours typically involved in obesity.

The lack of consensus on the target eating behaviours associated with obesity is in contrast with the eating disorders literature. A broad range of target eating behaviours have been identified as being of direct relevance to eating disorders such as anorexia nervosa, bulimia nervosa and binge eating disorder including, dietary restriction, binge eating, purging (e.g., self-induced vomiting, laxative misuse and excessive exercising), and body checking/avoidance (American Psychiatric Association, 2000). Other important non-behavioural psychological features have also been identified for various eating disorders such as the over-valuation of weight and shape, a disturbance of body experience and morbid fear of weight gain (Fairburn, 2008).

\section{Approaches to identifying target eating behaviours associated with obesity}

One approach to identifying the target eating behaviours in obesity is to ask "where do the excess calories come from?" For example, data from the National Health and Nutrition Examination Survey (a representative sample of the US population) confirm that increases in rates of obesity over time are associated with an increase in energy intake overall, as expected, and the authors recommend an overall decrease in energy consumption potentially through replacing carbohydrate and fat with protein (Austin, Ogden, \& Hill, 2011). Other studies have identified a range of specific eating behaviours that have changed in parallel with increasing rates of obesity, including increases in portion sizes and greater consumption of sweetened beverages (Nielsen \& Popkin, 2003, 2004).

However, there is no substitute for analysis of an individual patient's 'overeating,' This is important as dietitians note that for some people who are obese, high calorie food choices account for most of their excess calories, whereas other people who are obese primarily eat relatively healthy food, but eat portion sizes that are very large (Hebblethwaite, 2010).

Another approach to identifying the target eating behaviours in obesity is to examine the eating behaviour of people who successfully lose weight and keep it off. Reports using the USA's National Weight Control Registry (http://www.nwcr.ws) found that eating related measures associated with long term weight loss maintenance included: eating breakfast regularly, eating a low-calorie low-fat diet, maintaining a consistent eating pattern across weekdays and weekends, and decreased dietary disinhibition (Phelan et al., 2009; Wing \& Hill, 2001; Wing \& Phelan, 2005). It is important to note that these data are retrospective self-reports, obtained at least a year after people appeared to be successful in losing weight. It is not entirely clear whether these retrospectively reported successful dieting methods are the actual clue to success, and whether they differ from the methods that unsuccessful dieters report. A prospective randomized controlled trial indicated that lowering emotional eating and adopting a flexible dietary restraint pattern were critical for sustained weight loss (Teixeira et al., 2010). Decreased cue reactivity (salivation) has also been found to be associated with successful dieting (Bond, Phelan, Leahey, Hill, \& Wing, 2009; Bond, Raynor, McCaffery, \& Wing, 2010; Jansen, Stegerman, Roefs, Nederkoorn, \& Havermans, 2010). However, knowing which behaviours prevent or promote relapse after losing weight, might not simply be the opposite of the behaviours that cause or maintain the obesity.

Finally, although the focus of the current paper is on eating behaviours, it is interesting to note that variables relating to exercise and self-monitoring have also repeatedly been found to be associated with the maintenance of weight loss (Butryn, Phelan, Hill, \& Wing, 2007; Kruger, Blanck, \& Gillespie, 2006; Teixeira et al., 2010; Wadden et al., 2011; Wing \& Phelan, 2005).

\section{Self-report questionnaire}

Supplementary material shows a self-report questionnaire that aims to identify the target eating behaviours that are potentially involved in obesity, and that may need to be targeted to promote weight loss. This questionnaire examines current (past 3 months) eating behaviour, although it could easily be adapted to examine past eating behaviour. This questionnaire was developed taking account of the literature and clinical observations. As stated above, literature searches suggest that there is currently no clear empirical basis for stating what the full range of target behaviours are that are associated with obesity. It is hoped that this list will help researchers to examine the relative frequency of different eating behaviours that seem likely to be associated with obesity, and will help clinicians to consider a broad range of potential target eating behaviours when working with patients who struggle with their weight.

Feedback on a draft of the questionnaire was also sought by one of the authors (FC) from obese patients seeking bariatric surgery. In response to this patient feedback, "eating when feeling bored" was separated out from "eating when feeling 'bad' (e.g., upset, angry, anxious or stressed)", as it so commonly was the primary emotional trigger that patients identified as prompting eating. Also, "not eating enough in the first half of the day, and then overeating in the afternoon and/or evening" was asked in addition to "not eating breakfast" because many patients had difficulty with this, despite eating breakfast (light). Finally, "eating as an enjoyable thing to do" was asked separately from "eating as a reward," because the former was more commonly reported than the latter. Where possible, we have tried to describe the behaviour involved, rather than use labels such as "mindless eating," "all or none 
eating" or "emotional eating," to avoid any confusion over the interpretation of these terms. Also, we have tried to use language that is more accessible to lay people (e.g., "feeling bad") rather than using psychological terms (e.g., "negative affect").

This questionnaire is not exhaustive, and many of the eating behaviours described overlap. For example, it is common for people to graze while watching television or after not having eaten enough in the first half of the day. Also, we are not implying that these behaviours are confined to people who are obese. For example, anecdote would suggest that some people who regularly skip breakfast are not obese. While this questionnaire only examines eating behaviour, we acknowledge the important role of exercise and self-monitoring behaviours in weight management, and encourage assessment of these variables in their own right (Blair \& Brodney, 1999; Butryn et al., 2007; Fogelholm \& Kukkonen-Harjula, 2000; Kruger et al., 2006; Must \& Tybor, 2005; Shaw, Gennat, O’Rourke, \& Del Mar, 2009; Teixeira et al., 2010; Thompson, Jarvie, Lahey, \& Cureton, 1982; Wadden et al., 2011; Wing \& Phelan, 2005; Zoeller, 2007).

\section{Uneven focus of research}

Examination of the literature shows that some potential target eating behaviours for obesity identified in the self-report questionnaire (Supplementary material) have received more attention than others. For example, numerous clinical trials have evaluated interventions for people who binge eat (Brownley, Berkman, Sedway, Lohr, \& Bulik, 2007). However, most people who are obese do not report binge eating, which may partly explain why treatment trials for binge eating (Brownley et al., 2007) have not been conducted specifically for people who are obese. It is estimated that only around 5-8\% of obese people in the general population report binge eating, and approximately $20-30 \%$ of obese people in clinic samples report serious difficulties with binge eating (Marcus, 1995). Also, improvement in binge eating is not necessarily associated with significant weight loss (Wonderlich, de Zwaan, Mitchell, Peterson, \& Crow, 2003), and the presence of binge eating prior to bariatric surgery is an unreliable predictor of weight loss following surgery (Balasanova, 2010).

Therefore, it clearly would not be helpful for obesity treatment research to focus disproportionately on binge eating. Research is needed that uses observations of people who are obese as the starting point, rather than relying on concepts inherited from eating disorders research. For example, despite grazing being identified as a high risk behaviour for weight gain (Saunders, 2004a), it has received minimal attention. A Psychinfo search of the terms 'grazing' and 'obesity' provided only four journal articles, of which two were of interest. Both studies showed that grazing was related to weight regain following bariatric surgery (Colles, Dixon, \& O’Brien, 2008; Kofman, Lent, \& Swencionis, 2010). An additional study was found that reports treatment for "binge eating behaviour among bariatric surgery candidates," which included patients with a "graze eating pattern with loss of control" (Ashton et al., 2009).

In contrast to binge eating, grazing involves the repeated consumption of smaller amounts of food over an extended period of time. However, there is no current consensus on the definition of grazing. Some researchers include accompanying feelings of loss of control in the definition of grazing (Saunders, 2004a). The Eating Disorders Examination (Fairburn \& Cooper, 1993) defines 'picking (nibbling)' as eating in an unplanned and repetitious way. However, given that grazing can result in the consumption of excess calories, regardless of whether the person has accompanying feelings of loss of control or the eating is planned or unplanned, there may be advantages to identifying grazing behaviour in the first instance, and then noting the presence or absence of loss of control/ planning as specifiers.

The rates of grazing amongst people in the general population (obese and non-obese) are not even known. Amongst obese people seeking bariatric surgery, grazing is common before (26\%) and after (38\%) surgery, and the latter is associated with significantly less weight loss following surgery (Colles, Dixon, \& O'Brien, 2008) or more weight re-gain at longer term follow-up (Kofman et al., 2010). Unfortunately, in many work settings, patients are only eligible for State/insurance funded treatment if they meet criteria for a recognised eating disorder. Therefore, while eating behaviours such as grazing may be common and problematic in the context of obesity, patients with this difficulty (in the absence of recognised eating disorders) may not be eligible for treatment in some contexts.

\section{Assumptions about target eating behaviours}

It is important that we do not make unwarranted assumptions about the target eating behaviours involved in obesity. These target eating behaviours may not necessarily take the same form as they do amongst people who have a recognised eating disorder, or do not struggle with their weight. Again, this highlights the need for studies observing people who struggle with their weight in their natural environment.

It is also possible that the form that problematic eating behaviours take, changes over time. For example, while child researchers report no particular difficulty assessing binge eating amongst obese children (Tanofsky-Kraff, 2010), it has been the experience of one of the authors (FC) that people who are obese, middle aged, and presenting for bariatric surgery, often have considerable difficulty answering questions about their sense of control when eating a very large amount of food within a discrete period of time. Many of these people present as having 'given up' on dieting. When describing discrete episodes of clear overeating, these patients often do not clearly report 'loss of control' or 'a sense of lack of control' over eating. Therefore, these eating episodes do not meet criteria for binge eating (American Psychiatric Association, 1994), unless the assessor applies a liberal interpretation of the criteria (i.e., fudges it). The Eating Disorders Examination (Fairburn \& Cooper, 1993) allows for 'loss of control' to be rated if patients are "no longer trying to control their eating because overeating is inevitable" (p. 19). However, where there is no past history of clear loss of control, it would seem inaccurate to rate the current episodes of overeating as involving loss of control if patients do not report this.

In our view, there may be benefits to using a dimensional, rather than a dichotomous, measure of loss of control amongst patients who have episodes of overeating. It would seem preferable to listen to, and accept, what patients say about their experience of [lack of] control, rather than trying to force their accounts to 'fit' our dichotomous definitions. It is possible that psychological interventions that are useful in the treatment of binge eating, may also be helpful for people who have episodes of overeating not involving current clear loss of control (Nauta, Hospers, \& Jansen, 2001; Nauta, Hospers, Kok, \& Jansen, 2000).

\section{Context and consequences of target eating behaviours}

Following the identification of target eating behaviours, it is essential to develop a clear understanding of the context in which these behaviours occur and the consequences of these behaviours. This may provide a richer understanding of the role that these behaviours play, and help generate effective interventions.

While the present paper focuses primarily on behavioural targets for obesity, thoughts and feelings are profoundly important antecedents and/or consequences of target eating behaviours (Nauta, Hospers, Jansen, \& Kok, 2000). Beck provides numerous examples of the role of cognitions in promoting problem eating amongst people who are overweight, and suggests strategies for modifying these maladaptive thoughts (Beck, 2007a, 2007b). 
Similarly, feelings are often pivotal in understanding and modifying problem eating. Clinically, it is common for patients to describe themselves as being a "comfort eater" or an "emotional eater." This pattern of eating is clearly problematic in the context of obesity, and a considerable amount of research has been conducted in this area (e.g., see Adriaanse, de Ridder, \& Evers, 2011; Evers, de Ridder, \& Adriaanse, 2009; Evers, Marijn Stok, \& de Ridder, 2010). However, we do not have a consensus on the best way of describing this style of eating when talking with patients about this (i.e., shared terminology between clinicians and patients). Consequently, the clinician may find that the terms found in 'women's magazines' (such as 'comfort eater' or 'emotional eater') do a better job of capturing patients pattern of eating, and they may resonate better with patients, than the recognised nomenclature.

Once a pattern of eating in response to emotional cues is established, classical conditioning has taken place and less intense emotional cues may be needed to trigger eating. Also, the range of cues that can trigger eating may broaden. For example, one patient commented that she used to overeat "after something really bad happened," such as a fight with her boyfriend, but that over time she would overeat "with any emotion" (i.e., positive/negative, mild/intense). The implication of this is that once this pattern of responding is established, it may be less obvious to the patient, clinician and researcher that eating is playing a role in emotional regulation as the required cues may be weaker, less salient and more diverse. However, it may still be useful to help the patient to develop alternative, more adaptive ways of managing emotional states, including seemingly innocuous states such as 'boredom.'

It is also important not to underestimate how difficult it may be for some patients to find alternative pleasurable behaviours to replace eating. Food is cheap, legal, easily obtained, highly reinforcing and can be consumed in the privacy of your own home. Lowe (Lowe \& Butryn, 2007) argues that human food consumption is increasingly driven by pleasure, rather than just by the need for calories. However, there is some evidence that people who are obese engage in more 'hedonic eating' than people who are not obese (Blundell \& Finlayson, 2004; Lowe \& Butryn, 2007), and will work harder than people who are not obese to get high calorie foods (Giesen, Havermans, Douven, Tekelenburg, \& Jansen, 2010). After many years of using food as a pleasure, patients and clinicians need to expect that it may take quite some time to develop effective alternative pleasurable behaviours, and that these behaviours may not be as enjoyable as eating, especially in the short term. However, clinicians should not assume that patients who state that they "simply love food" have a dearth of pleasurable behaviours other than eating, as this is not always the case.

Obesity itself may make it more difficult for patients and clinicians to develop a range of alternative pleasurable activities that are realistic and feasible for patients to implement. For example, people who are very overweight may find it difficult to engage in physical activities that they previously enjoyed due to chronic pain (e.g., joint problems related to weight difficulties) and tiredness (in part related to poor quality sleep). The stigma associated with obesity may also mean that some people feel self-conscious engaging in previously enjoyable activities such as swimming in public pools or being the focus of attention in social settings.

Contextual cues of relevance to eating include the setting where the eating occurs, and other behaviours that may be combined with eating. For example, patients may describe typically eating while watching television, standing at the bench while preparing a meal, being on the computer, driving or even being in bed. Sometimes meals may be eaten at the table, but grazing on high calorie food will occur in one of these other settings. As with other health behaviours (Orbell \& Verplanken, 2010) context-induced (over) eating often occurs automatically, without the person being aware of what they are doing (Rothman, Sheeran, \& Wood, 2009; Wood \& Neal, 2007). Automatic habitual overeating to everyday cues within the environment correlates with weight gain and obesity and is difficult to control (Hays \& Roberts, 2008). Increased susceptibility to internal and external cues that trigger overeating may also increase the risk of weight (re)gain (Bond et al., 2009; Jansen, Havermans, \& Nederkoorn, 2011; Niemeier, Phelan, Fava, \& Wing, 2007). Predictably, responding to internal and external cues with decreased restraint and increased disinhibited eating is associated with increased body mass index (Ferriday \& Brunstrom, 2011; Hays \& Roberts, 2008; Jansen et al., 2003). A clear understanding of the context in which problematic eating occurs, and people's response to these cues, may help to generate potential treatment strategies.

Similarly, a full understanding of the consequences of target eating behaviours is helpful for both the patient and the clinician. This information is useful in psycho-education (e.g., formulating an individualised model of factors involved in overeating for the patient) and may help suggest intervention strategies for that patient. It is useful to consider the immediate and delayed consequences of target behaviours, plus the full range of possible consequences, such as physiological, emotional, behavioural and social consequences.

\section{Treatment directions}

Finally, it is necessary to identify effective treatments. Given the status of cognitive behaviour therapy (CBT) as a treatment for disordered eating (Fairburn, 2008), it seems likely that psychological treatment for obesity will focus on CBT treatment packages. However, a recent CBT trial found disappointing results for weight loss and weight maintenance amongst people who were obese (Cooper et al., 2010). Questions have been raised concerning whether this trial evaluated standard CBT for eating disorders or a new cognitive behavioural treatment for obesity (Jeffery \& Levy, 2010). A small number of trials have found that pure cognitive therapy can play an effective role in weight loss and weight maintenance (Stahre \& Hallstrom, 2005; Stahre, Tarnell, Hakanson, \& Hallstrom, 2007; Werrij et al., 2009). For example, adding cognitive therapy to dietetic treatment was found to be more effective at reducing relapse in comparison with adding physical exercise to dietetic treatment (Werrij et al., 2009). It has been suggested that cognitive restructuring might have a prophylactic effect in helping to prevent relapse and maintain weight loss over the longer term (Werrij et al., 2009).

Appetite focused CBT helps people to become more aware of hunger and satiety signals, and learn ways to respond appropriately to these cues (McIntosh, Jordan, Carter, Latner, \& Wallace, 2007). This approach is currently being evaluated in a randomised controlled trial amongst people with binge eating disorder (Joyce et al., 2004). It may be useful to conduct similar trials with people who are obese (regardless of whether they meet criteria for binge eating disorder or not) to see if this approach helps people to reduce their portion sizes and grazing.

In terms of specific target eating behaviours associated with obesity, few studies have reported evaluating a treatment for grazing that was effective (Ashton et al., 2009; Saunders, 2004b). Both of these studies involved group treatment in a specific context (bariatric surgery) for a heterogeneous mix of patients that included patients with binge eating rather than grazing. Appendix B presents a case vignette and possible treatment strategies for problematic grazing. Cognitive behavioural strategies are suggested, given that this is the only approach where there are known studies reporting a positive outcome in the treatment of grazing (Ashton et al., 2009; Saunders, 2004b). However, it is likely that other treatment approaches (e.g., mindfulness based approaches) 
may also be useful in the treatment of grazing, and they should also be evaluated.

While treatment packages are appealing, ideally we need a stronger research basis for saying which interventions are most effective for which targets, when designing treatment packages. A number of unanswered questions remain concerning specific psychological strategies in the context of obesity treatment research. For example, have we exhausted all potentially effective psychological techniques? Do we have any approaches that have been effective in other areas that might be worth evaluating in the context of obesity? Are different strategies needed for different target eating behaviours?

Selected examples of psychological approaches that the literature suggests may warrant further exploration in the area of obesity are described below. A broad approach to 'psychological techniques' has been taken to include more than just behavioural approaches.

Dissonance-inducing activities are known to be more effective at altering eating symptoms than other psychological techniques (Stice, Chase, Stormer, \& Appel, 2001; Stice, Shaw, Burton, \& Wade, 2006; Yager \& O'Dea, 2008). It is possible that dissonance approaches may also be effective at reducing the purchasing of high calorie takeaway foods amongst people who are obese.

Cue exposure with response prevention has the potential to improve treatment outcome for obesity, and importantly, to help people be more resistant to relapse (Jansen et al., 2011). Traditionally, dieting strategies have often involved the avoidance of exposure to cues and contexts that are associated with (excessive) intake (e.g., the removal of high calorie food from the house and avoiding entering bakeries). While this may have benefits in the short term, total avoidance of highly palatable food is not possible in the longer term. Also, some conditioned cues for overeating are more difficult to control and avoid (e.g., feeling angry after a bad day at work). Cue exposure with response prevention aims to reduce reactivity to the cues involved in overeating. If successful, dieting would presumably be easier and more effective. Although cue exposure with response training would be expected to be effective in reducing cued overeating (Jansen, 1998; Jansen et al., 2011), no known studies have systematically evaluated its effectiveness in the context of obesity. Treatment would involve the patient being repeatedly exposed to cues or contexts that have previously predicted overeating, with response prevention (i.e., no eating). In this way, the old response associations would be extinguished and a new inhibitory association between cues/contexts/emotions and eating would be learned (e.g., if sad, no eating). Ideally, cue exposure would be individualised following a thorough assessment to ensure that the individual was exposed to the cues and contexts that are most powerful and relevant for them. While in vivo exposure has many advantages (Rohsenow, Monti, \& Abrams, 1995), imaginal exposure may be necessary for some cues and contexts (e.g., feeling upset after a fight with your partner).

\section{Conclusion}

In this opinion piece, we highlight that people who are obese and want to lose weight without surgery deserve the best treatment that we can offer. Research is needed that uses observations of people who are obese as the starting point, rather than relying on concepts inherited from eating disorders research. In order to develop effective interventions, we need a clearer understanding of the full range of specific target eating behaviours involved in obesity, and a full understanding of the mechanisms maintaining these behaviours. Effective interventions need to be systematically evaluated for the full range of problematic target eating behaviours, including grazing. We provide a self-report questionnaire that aims to identify the target behaviours that are likely to be involved in obesity.

\section{References}

Adriaanse, M. A., de Ridder, D. T., \& Evers, C. (2011). Emotional eating. Eating when emotional or emotional about eating? Psychology and Health, 26, 23-39.

Allison, K. C., Lundgren, J. D., O'Reardon, J. P., Geliebter, A., Gluck, M. E., Vinai, P., et al. (2010). Proposed diagnostic criteria for night eating syndrome. International Journal of Eating Disorders, 43, 241-247.

American Psychiatric Association (1994). Diagnostic and statistical manual of mental disorders, IV (4th ed.). Washington, DC: American Psychiatric Association.

American Psychiatric Association (2000). Diagnostic and statistical manual of mental disorders (revised 4th ed.). Washington, DC: American Psychiatric Association.

Ashton, K., Drerup, M., Windover, A., \& Heinberg, L. (2009). Brief, four-session group CBT reduces binge eating behaviors among bariatric surgery candidates. Surgery for Obesity and Related Diseases, 5, 257-262.

Austin, G. L., Ogden, L. G., \& Hill, J. O. (2011). Trends in carbohydrate, fat, and protein intakes and association with energy intake in normal-weight, overweight, and obese individuals, 1971-2006. American Journal of Clinical Nutrition, 93, 836-843.

Balasanova, A. A. (2010). Making sense of the research regarding binge eating and bariatric surgery outcomes. Bariatric Times, 7, 8-11.

Barte, J. C., ter Bogt, N. C., Bogers, R. P., Teixeira, P. J., Blissmer, B., Mori, T. A., et al. (2010). Maintenance of weight loss after lifestyle interventions for overweight and obesity, a systematic review. Obesity Reviews, 11, 899-906.

Beck, J. S. (2007a). The Beck Diet Solution. Train your brain to think like a thin person. Alabama: Oxmoor House, Inc..

Beck, J. S. (2007b). The Beck Diet Solution: Weight Loss Workbook. Alabama: Oxmoor House, Inc.

Blair, S. N., \& Brodney, S. (1999). Effects of physical inactivity and obesity on morbidity and mortality. Current evidence and research issues. Medicine and Science in Sports and Exercise, 31, S646-S662.

Blundell, J. E., \& Finlayson, G. (2004). Is susceptibility to weight gain characterized by homeostatic or hedonic risk factors for overconsumption? Physiology $\mathcal{E}$ Behavior, 82, 21-25.

Bond, D. S., Phelan, S., Leahey, T. M., Hill, J. O., \& Wing, R. R. (2009). Weight-loss maintenance in successful weight losers. Surgical vs non-surgical methods. International Journal of Obesity, 33, 173-180.

Bond, D. S., Raynor, H. A., McCaffery, J. M., \& Wing, R. R. (2010). Salivary habituation to food stimuli in successful weight loss maintainers, obese and normal-weight adults. International Journal of Obesity, 34, 593-596.

Brownell, K. D. (2010). The humbling experience of treating obesity. Should we persist or desist? Behaviour Research and Therapy, 48, 717-719.

Brownley, K. A., Berkman, N. D., Sedway, J. A., Lohr, K. N., \& Bulik, C. M. (2007). Binge eating disorder treatment. A systematic review of randomized controlled trials. International Journal of Eating Disorders, 40, 337-348.

Butryn, M. L., Phelan, S., Hill, J. O., \& Wing, R. R. (2007). Consistent self-monitoring of weight. A key component of successful weight loss maintenance. Obesity (Silver Spring), 15, 3091-3096.

Colles, S. L., Dixon, J. B., \& O’Brien, P. E. (2008). Grazing and loss of control related to eating. Two high-risk factors following bariatric surgery. Obesity (Silver Spring), $16,615-622$.

Cooper, Z., Doll, H. A., Hawker, D. M., Byrne, S., Bonner, G., Eeley, E., et al. (2010). Testing a new cognitive behavioural treatment for obesity. A randomized controlled trial with three-year follow-up. Behaviour Research and Therapy, 48, 706-713.

Cooper, Z., Fairburn, C., \& Hawker, D. M. (2003). Cognitive behavioural treatment of obesity. A clinician's guide. New York: The Guilford Press.

Evers, C., de Ridder, D. T., \& Adriaanse, M. A. (2009). Assessing yourself as an emotional eater. Mission impossible? Health Psychology, 28, 717-725.

Evers, C., Marijn Stok, F., \& de Ridder, D. T. (2010). Feeding your feelings. Emotion regulation strategies and emotional eating. Personality and Social Psychology Bulletin, 36, 792-804.

Fairburn, C. (2008). Cognitive behavior therapy and eating disorders. London: The Guilford Press.

Fairburn, C. G., \& Cooper, Z. (1993). The eating disorder examination. In C. G. Fairburn \& G. T. Wilson (Eds.), Binge-eating. Nature, assessment and treatment (pp. 317-360). New York: The Guilford Press.

Ferriday, D., \& Brunstrom, J. M. (2010). 'I just can't help myself. Effects of food-cue exposure in overweight and lean individuals. International Journal of Obesity (London), 35, 142-149.

Flum, D. R., Belle, S. H., King, W. C., Wahed, A. S., Berk, P., Chapman, W., et al. (2009). Perioperative safety in the longitudinal assessment of bariatric surgery. New England Journal of Medicine, 361, 445-454.

Fogelholm, M., \& Kukkonen-Harjula, K. (2000). Does physical activity prevent weight gain. A systematic review. Obesity Reviews, 1, 95-111.

Giesen, J. C. A. H., Havermans, R. C., Douven, A., Tekelenburg, M., \& Jansen, A. (2010). Will work for snack food. The association of BMI and snack reinforcement. Obesity, 18, 966-970.

Hays, N. P., \& Roberts, S. B. (2008). Aspects of eating behaviors "disinhibition" and "restraint" are related to weight gain and BMI in women. Obesity, 16, 52-58.

Hebblethwaite, C. (2010). In F. A. Carter (Ed.), Different dietary reasons for people being obese. Christchurch, New Zealand. 
Hevener, A. L., \& Febbraio, M. A. (2010). The 2009 stock conference report. Inflammation, obesity and metabolic disease. Obesity Reviews, 11, 635-644.

Jansen, A. (1998). A learning model of binge eating. Cue reactivity and cue exposure. Behaviour Research and Therapy, 36, 257-272.

Jansen, A., Havermans, R., \& Nederkoorn, C. (2011). Cued overeating. New York: Springer.

Jansen, A., Stegerman, S., Roefs, A., Nederkoorn, C., \& Havermans, R. (2010). Decreased salivation to food cues in formerly obese successful dieters. Psychotherapy and Psychosomatics, 79, 257-258.

Jansen, A., Theunissen, N., Slechten, K., Nederkoorn, C., Boon, B., Mulkens, S., et al. (2003). Overweight children overeat after exposure to food cues. Eating Behaviors, 4, 197-209.

Jeffery, R. W., \& Levy, R. L. (2010). Overgeneralization from limited data. A commentary on Cooper et al., 2010. Behaviour Research and Therapy, 48, 714-716.

Joyce, P. R., McIntosh, V. V. W., Jordan, J., Carter, J. D., McKenzie, J. M., \& Frampton, C. (2004). Enhancing psychotherapy for bulimia nervosa and binge eating. A randomised controlled trial of cognitive behaviour therapy, schema therapy and appetite-focused CBT. Funded by the Health Research Council of New Zealand. Christchurch, New Zealand: Health Research Council Project and Programme Grants.

Kofman, M. D., Lent, M. R., \& Swencionis, C. (2010). Maladaptive eating patterns, quality of life, and weight outcomes following gastric bypass. Results of an Internet survey. Obesity (Silver Spring), 18, 1938-1943.

Kopelman, P. (2007). Health risks associated with overweight and obesity. Obesity Reviews, 8(Suppl. 1), 13-17.

Kruger, J., Blanck, H. M., \& Gillespie, C. (2006). Dietary and physical activity behaviors among adults successful at weight loss maintenance. International Journal of Behavioral Nutrition and Physical Activity, 3, 17.

Laessle, R. G. (2005). Treatment options of obesity. Behavioral weight control. In S. Munsch \& C. Beglinger (Eds.), Obesity and binge eating. New York: Karger.

Lowe, M. R., \& Butryn, M. L. (2007). Hedonic hunger. A new dimension of appetite? Physiology \& Behavior, 91, 432-439.

Marcus, M. D. (1995). Binge eating and obesity. In K. D. Brownell \& C. G. Fairburn (Eds.), Eatings disorders and obesity. A comprehensive handbook (pp. 441-444). New York: The Guildford Press.

McIntosh, V. V. W., Jordan, J., Carter, J. D., Latner, J. D., \& Wallace, A. (2007). Appetite focused CBT for binge eating. In G. T. Wilson \& J. D. Latner (Eds.), Self-help for obesity and eating disorders. New York: The Guilford Press.

Must, A., \& Tybor, D. J. (2005). Physical activity and sedentary behavior. A review of longitudinal studies of weight and adiposity in youth. International Journal of Obesity, 29(Suppl. 2), S84-S96.

Nauta, H., Hospers, H., \& Jansen, A. (2001). One-year follow-up effects of two obesity treatments on psychological well-being and weight. British Journal of Health Psychology, 6, 271-284.

Nauta, H., Hospers, H. J., Jansen, A., \& Kok, G. (2000). Cognitions in obese binge eaters and obese non-binge eaters. Cognitive Therapy and Research, 24, 521-531.

Nauta, H., Hospers, H., Kok, G., \& Jansen, A. (2000). A comparison between a cognitive and a behavioral treatment for obese binge eaters and obese nonbinge eaters. Behavior Therapy, 31, 441-461.

Nielsen, S. J., \& Popkin, B. M. (2003). Patterns and trends in food portion sizes, 19771998. JAMA, 289, 450-453.

Nielsen, S. J., \& Popkin, B. M. (2004). Changes in beverage intake between 1977 and 2001. American Journal of Preventive Medicine, 27, 205-210.

Niemeier, H. M., Phelan, S., Fava, J. L., \& Wing, R. R. (2007). Internal disinhibition predicts weight regain following weight loss and weight loss maintenance. Obesity (Silver Spring), 15, 2485-2494.

Orbell, S., \& Verplanken, B. (2010). The automatic component of habit in health behavior. Habit as cue-contingent automaticity. Health Psychology, 29, 374-383.

Phelan, S., Liu, T., Gorin, A., Lowe, M., Hogan, J., Fava, J., et al. (2009). What distinguishes weight-loss maintainers from the treatment-seeking obese? Analysis of environmental, behavioral, and psychosocial variables in diverse populations. Annals of Behavioral Medicine, 38, 94-104.

Rohsenow, D. J., Monti, P. M., \& Abrams, D. B. (1995). Cue exposure treatment in alcohol dependence. In Addictive behaviour, cue exposure theory and practice. West Sussed: Wiley.

Rothman, A. J., Sheeran, P., \& Wood, W. (2009). Reflective and automatic processes in the initiation and maintenance of dietary change. Annals of Behavioral Medicine, 38(Suppl. 1), S4-S17.
Saunders, R. (2004a). “Grazing”. A high-risk behavior. Obesity Surgery, 14, 98-102.

Saunders, R. (2004b). Post-surgery group therapy for gastric bypass patients. Obesity Surgery, 14, 1128-1131.

Shaw, K., Gennat, H., O'Rourke, P., \& Del Mar, C. (2009). Exercise for overweight or obesity. Cochrane Database of Systematic Reviews. doi:10.1002/ 14651858.CD003817.pub3.

Smith West, D., Gore, S., \& Lueders, N. (2007). Behavioral obesity treatment translated. In J. Latner \& G. T. Wilson (Eds.), Self-help approaches for obesity and eating disorders (pp. 243-264). New York: The Guilford Press.

Stahre, L., \& Hallstrom, T. (2005). A short-term cognitive group treatment program gives substantial weight reduction up to 18 months from the end of treatment A randomized controlled trial. Eating and Weight Disorders, 10, 51-58.

Stahre, L., Tarnell, B., Hakanson, C. E., \& Hallstrom, T. (2007). A randomized controlled trial of two weight-reducing short-term group treatment programs for obesity with an 18-month follow-up. International Journal of Behavioral Medicine, 14, 48-55.

Stice, E., Chase, A., Stormer, S., \& Appel, A. (2001). A randomized trial of a dissonance-based eating disorder prevention program. International Journal of Eating Disorders, 29, 247-262.

Stice, E., Shaw, H., Burton, E., \& Wade, E. (2006). Dissonance and healthy weight eating disorder prevention programs. A randomized efficacy trial. Journal of Consulting \& Clinical Psychology, 74, 263-275.

Stuart, R. B. (1967). Behavioral control of overeating. Behaviour Research and Therapy, 5, 357-365.

Stunkard, A., Berkowitz, R., Wadden, T., Tanrikut, C., Reiss, E., \& Young, L. (1996). Binge eating disorder and the night-eating syndrome. International Journal of Obesity and Related Metabolic Disorders, 20, 1-6.

Sturm, R. (2002). The effects of obesity, smoking, and drinking on medical problems and costs. Health Affairs, 21, 245-253.

Tanofsky-Kraff, M. (2010). In F. A. Carter (Ed.), The assessment of loss of control amongst children who binge eat. Amsterdam, The Netherlands.

Teixeira, P. J., Silva, M. N., Coutinho, S. R., Palmeira, A. L., Mata, J., Vieira, P. N., et al. (2010). Mediators of weight loss and weight loss maintenance in middle-aged women. Obesity (Silver Spring), 18, 725-735.

Thompson, J. K., Jarvie, G. J., Lahey, B. B., \& Cureton, K. J. (1982). Exercise and obesity Etiology, physiology, and intervention. Psychological Bulletin, 91, 55-79.

Wadden, T. A., Neiberg, R. H., Wing, R. R., Clark, J. M., Delahanty, L. M., Hill, J. O., et al. (2011). Four-year weight losses in the Look AHEAD study. Factors associated with long-term success. Obesity (Silver Spring), 19, 1987-1998.

Wadden, T., \& Phelan, S. (2002). Behavioral assessment of the obese patient. In Handbook of obesity treatment (pp. 186-229). New York: The Guilford Press.

Wadden, T., \& Stunkard, A. (2002). Handbook of obesity treatment. New York: The Guilford Press.

Werrij, M. Q., Jansen, A., Mulkens, S., Elgersma, H. J., Ament, A. J., \& Hospers, H. J. (2009). Adding cognitive therapy to dietetic treatment is associated with less relapse in obesity. Journal of Psychosomatic Research, 67, 315-324.

Wilson, G. T. (1995). Behavioral approaches to the treatment of obesity. In K. D. Brownell \& C. G. Fairburn (Eds.), Eating Disorder and Obesity. A Comprehensive Handbook (pp. 479-483). New York: The Guildford Press.

Wing, R. R., \& Hill, J. O. (2001). Successful weight loss maintenance. Annual Review of Nutrition, 21, 323-341.

Wing, R. R., \& Phelan, S. (2005). Long-term weight loss maintenance. American Journal of Clinical Nutrition, 82, 222s-225s.

Wonderlich, S. A., de Zwaan, M., Mitchell, J. E., Peterson, C., \& Crow, S. (2003) Psychological and dietary treatments of binge eating disorder. Conceptual implications. International Journal of Eating Disorders, 34(Suppl.), S58-S73.

Wood, W., \& Neal, D. T. (2007). A new look at habits and the habit-goal interface Psychological Review, 114, 843-863.

World Health Organization. (2011). 2010 obesity rates. Available from https:// apps.who.int/infobase/Comparisons.aspx.

Wu, T., Gao, X., Chen, M., \& van Dam, R. M. (2009). Long-term effectiveness of dietplus-exercise interventions vs. diet-only interventions for weight loss. A metaanalysis. Obesity Reviews, 10, 313-323.

Yager, Z., \& O'Dea, J. A. (2008). Prevention programs for body image and eating disorders on University campuses. A review of large, controlled interventions (review). Health Promotion International, 23, 173-189.

Zoeller, R. F. Jr., (2007). Physical activity and obesity. Their interaction and implications for disease risk and the role of physical activity in health weight management. American Journal of Lifestyle Medicine, 1, 437-446. 


\section{Appendix A. Supplementary data}

Supplementary data associated with this article can be found, in the online version, at doi:10.1016/j.appet.2012.01.016.

\section{Appendix B. Grazing: A Cinderella concept in obesity research?}

\section{What is grazing?}

Grazing involves the repeated consumption of smaller amounts of food over an extended period of time. The late afternoon and evening seem to be common high risk times for grazing, although grazing can occur at any time. Often the types of food eaten are high calories foods.

Possible components of a treatment package

Cognitive behavioural strategies have been found to be effective in the treatment of grazing (Ashton et al., 2009; Saunders, 2004b). Cognitive behavioural techniques that could be applied to grazing including the following:

- Psycho-education

- Self-monitoring

- Prescription of regular eating, including eating breakfast

- Assistance identifying hunger and satiety signals

- Stimulus control strategies (e.g., separation of eating and watching television)

- Eat in a 'mindful' way

- Identification of cues for grazing (physical, emotional, situational, etc.)

- Development of more adaptive ways of meeting emotional needs, including alternative pleasurable behaviours

- Encouragement of behaviours incompatible with grazing (e.g., going for a walk)

- Identification of cognitions that promote and maintain grazing (e.g., "I am fat anyway, so what does it matter?")

- Cognitive strategies (e.g., challenging maladaptive thoughts, thought restructuring, chaining)

- Learning how to eat high risk foods in a 'safe' way (e.g., low risk time and place, support person present)

- Relapse prevention

\section{Case vignette*}

Alison is a woman who is 50 years of age and has a body mass index of 43 . She reports a longstanding history of struggling with her weight. Currently, she has significant pain from arthritis in her knees that her doctor tells her would be improved if she could reduce her weight. She describes the following pattern of eating.

Alison normally skips breakfast as she says that she does not feel hungry. She often has something to eat at morning tea break, but frequently she doesn't find time for lunch as she is busy at work. She has several coffees during the day which seem to keep her going. When Alison gets home from work around $3 \mathrm{pm}$ she feels exhausted. Her partner does not get home from work until late, so she is home alone. She has a snack (e.g., a sandwich) when she gets home, but does not feel satisfied or full after eating. She then starts snacking on high calorie foods such as crisps, cheese and crackers, chocolate and biscuits over several hours (multiple small snacks spread out over approximately $3 \mathrm{~h}$ ), while watching television and preparing the evening meal. She is unsure if she feels hungry or not at these times. Triggers for grazing seem to be: not having eaten enough in the first half of the day, feeling bored, lonely and like she deserves a treat after a hard day's work, and having tasty foods in the house. While she describes herself as being a 'comfort eater,' she states that nothing needs to have gone wrong in her day for her to eat like this. She states that she does not feel out of control while she eats and that this is "just a habit." She does not report making herself vomit after these eating episodes, or report using any other inappropriate compensatory behaviours such as laxative misuse. In the past she has been able to avoid grazing in the late afternoon by eating breakfast and going out for a walk after work. Currently however, she finds it hard to eat breakfast and her joint pain has worsened since she has gained weight, which makes walking unappealing. Alison is annoyed with herself for eating in this way as she knows it is contributing to her weight and pain problems, however she feels stuck in this pattern of eating.

Comment

Although clearly problematic, this pattern of eating does not meet criteria for binge eating disorder, bulimia nervosa, EDNOS (American Psychiatric Association, 1994) or night eating syndrome (Allison et al., 2010; Stunkard et al., 1996). Although grazing is significantly contributing to this woman's weight difficulties, few clinical trials (Ashton et al., 2009; Saunders, 2004b) have evaluated the effectiveness of interventions for grazing. In this sense, grazing is something of a 'Cinderella concept' in eating disorders research.

*In order to protect patient confidentiality, this 'case' is an amalgam of several typical cases. 